\title{
Virtual Reality Exposure for PTSD (Post-Traumatic Stress Disorder): A Systematic Review Virtual Reality PTSD Systematic Review
}

\author{
Marcelo Montagner Rigoli, Christian Haag Kristensen \\ Centre of Studies and Research in Traumatic Stress (NEPTE), \\ Pontifical Catholic University of Rio Grande do Sul (PUCRS), Porto Alegre, Brazil
}

\begin{abstract}
The objective of the present study is a systematic review on the use of VRE (Virtual Reality Exposure) for PTSD (Post-Traumatic Stress Disorder). The following keywords were used: PTSD, Post-Traumatic Stress Disorder, Posttraumatic Stress Disorder, Virtual Reality in these databases: PsycINFO/PsycLIT, PubMed/Medline, EBSCO, ProQuest, ISI Web of Science, and SciELO/Pepsic. The studies included should have their own empirical data and the intervention should consist of exposure to virtual reality. A total of 241 publications were found, of which 28 were selected for this review: 11 case studies, eight uncontrolled case series, and nine randomized controlled trials. The treatment ranged between 3 and $22 \operatorname{VRE}$ sessions $(M($ Mean $)=9.09, S D$ (standard deviation $)=1.57)$. Among the case studies, the results were promising; all studies were able to reduce the PTSD symptomatology. As to the uncontrolled case series, overall they showed promising results. Regarding the randomized clinical trials, there was found a wide variation concerning the VRE intervention as well as the combined and control intervention. The majority of the studies presented significant results, except two which returned modest or non-significant results. The findings of this study suggest that the use of virtual reality as a tool for exposure therapy for PTSD can be an asset.
\end{abstract}

Keywords: stress disorders, posttraumatic, VRE (Virtual Reality Exposure), therapy, review, systematic, psychotherapy

\section{Introduction}

PTSD (Post-Traumatic Stress Disorder) is defined as a symptomatic answer to a traumatic event involving recollections, avoidance, numbing, and increased arousal. It is a disturbance that causes clinically significant distress or functional impairment, with presence of symptoms for more than one month (American Psychiatric Association, 2000). The lifetime prevalence of PTSD has been estimated at $6.8 \%$ among the general population (Kessler, Chiu, Demler, \& Walters, 2005). Although women are less likely to be exposed to traumatic stressors events, they show greater prevalence of the disorder, as well as more conditional risk to develop PTSD after exposure to a particular traumatic event (Breslau, 2002). PTSD has been considered the fifth most common

Marcelo Montagner Rigoli, psychologist, Centre of Studies and Research in Traumatic Stress (NEPTE), Pontifical Catholic University of Rio Grande do Sul (PUCRS).

Christian Haag Kristensen, Ph.D., psychologist, Centre of Studies and Research in Traumatic Stress (NEPTE), Pontifical Catholic University of Rio Grande do Sul (PUCRS). 
mental disorder (Kessler et al., 2005), producing significant social and economic consequences (Ballenger et al., 2004). Economic costs associated with PTSD include absence from work and medical care costs. Individuals diagnosed with PTSD are also more likely to receive medical attention for psychological and general medical problems (Schnurr, Green, \& Kaltman, 2007; Taylor, 2006).

Patients with PTSD are at increased risk of other disorders of the anxiety spectrum, such as panic disorder, agoraphobia, obsessive-compulsive disorder, social phobia, and specific phobias (Kessler, 1995). Additionally, PTSD shows high comorbidity with mood disorders and disorders related to substances (Kessler et al., 2005; Mills, Teesson, Ross, \& Peters, 2006; Thomas et al., 2010). Once PTSD is diagnosed, these comorbidities must be examined; at least one additional psychiatric disorder was found in approximately $80 \%$ of the individuals with PTSD (Kessler et al., 2005). The role of comorbidities in treatment outcomes is still a matter of discussion in the literature. A recent meta-analysis showed, controversially, that the interaction between different psychopathologies has a positive correlation with effect size, including PTSD (Olatunji, Cisler, \& Deacon, 2010).

The earlier cognitive-behavioral interventions in PTSD were based on Mowrer's Two Factor Model (Mowrer, 1960), including mechanisms of classical and operant conditioning. Subsequently, the interventions became focused on the disorder's symptoms, such as PE (the prolonged exposure) (Rothbaum, Meadows, Resick, \& Foy, 2008), based on Foa and Kosik's EPT (emotional processing theory) (Foa \& Kozak, 1986). This theory states that there are fear structures activated by stimuli related to the traumatic event experienced, which trigger psychological and physiological reactions. In terms of its origins, this mechanism should work like a base plan in order that one could face a treacherous situation, either with fight or flight response. However, in PTSD, most of these connections represent erroneous associations, whereby stimuli that should be neutral are conditioned to the fear response, which could be related to intrusive symptoms characteristic to the disorder. Treatments, therefore, should aim to modify these dysfunctional elements from the fear structure until it decreases the capacity of neutral stimuli to elicit anxiety responses (Cahill \& Foa, 2007).

CBT (cognitive-behavioral therapy), in its classical form, is a well established treatment for PTSD. Also, the use of exposure alone or as part of a CBT protocol has been shown to be highly effective (Bisson, Ehlers, Matthews, Pilling, Richards, \& Turner, 2007; Bradley, Greene, Russ, Dutra, \& Westen, 2005; Mendes, Mello, Ventura, de Medeiros Passarela, \& de Jesus Mari, 2008). There are several ways to proceed with the exposure technique, but there are common aspects, such as the development of an anxiety hierarchy of trauma related situations and the confrontation of frightening/anxiogenic stimuli. The following exposure modalities can be used: flooding, in which the patient has to confront the most anxiogenic elements of the hierarchy (Taylor, 2006); imaginal (or "in vitro"), wherein the subject has to confront his or her memories of the traumatic event - the patient providing a narrative in the first person and the present tense; and "in vivo", where the subject has to face a real situation involving the traumatic event (Rothbaum et al., 2008). Recently, virtual reality technology has been applied to exposure treatment ("in virtuo" exposure).

The VRE cognitive-behavioral therapy for PTSD is based on the principles of PE (Riggs, Cahill, Foa, Follette, \& Ruzek, 2006). In its classical format, the PE is performed over 9 to 12 sessions of 90 minutes each. The treatment is divided into four parts: (1) psychoeducation about the disorder, the experienced trauma, and the reactions these events may trigger; (2) respiratory training, as a relaxing technique; (3) "in vivo" exposure in situations related by the patient to the trauma that he/she has, since then, avoided; and (4) imaginal exposure, whereby the patient recalls continually, in session, the memories related to the trauma, and which, 
by the end of the session are discussed, as well as the feelings and thoughts that occur with them. VR (virtual reality) can be used as a way of increasing the patient's emotional engagement in the exposure tasks (Reger \& Gahm, 2008).

Additional advantages are highlighted in the literature for the use of VR as a tool for the treatment of anxiety disorders (Wiederhold \& Wiederhold, 2004): (1) easier viewing for patients who have difficulty visualizing the traumatic event; (2) the opportunity of the therapists to visualize what the patient sees; (3) the possibility of the virtual exposure to be more realistic than the exposure based on mental imagery; and (4) the VR seems to increase the engagement of the patients in the treatment more than the imagery exposure. Despite its novelty, the use of VR as a tool for exposure therapy has returned promising results in terms of anxiety disorders; a meta-analysis showed a considerable effect size (Cohen's $d=1.11$ ) for specific phobia, social phobia, PTSD, and panic disorder (Powers \& Emmelkamp, 2008). Nonetheless, apart from its potential use, little is known about VR exposure in PTSD. Powers and Emmelkamp's (Powers \& Emmelkamp, 2008) review included only one paper in which the intervention focused on PTSD. As far as we know, none of the systematic reviews or meta-analysis of VR exposure as a treatment for PTSD can be found in the Cochrane Library.

The present study aims to perform a systematic research of publications containing empirical data that uses virtual reality exposure as an intervention for PTSD. Such a resource is a novelty in the area and a review that summarizes the already obtained data is an imperative. While this review was under construction, another review was published on the subject (Gonçalves, Pedrozo, Coutinho, Figueira, \& Ventura, 2012), which had stricter exclusion criteria, and further comments will be made in the discussion section. We hypothesize that virtual reality exposure will be effective since: (1) It has the potential to increase a patient's engagement and a therapist's control of the treatment; and (2) Other exposure techniques are already well established treatments (Rothbaum et al., 2008).

\section{Methods}

In order to search the electronic databases, the following keywords were used: PTSD, Post-Traumatic Stress Disorder, Posttraumatic Stress Disorder, Virtual Reality. The databases used for the search were: PsycINFO/PsycLIT, PubMed/Medline, EBSCO, ProQuest, ISI Web of Science and SciELO/Pepsic. Each database has its own search engine with diverse resources. However, we used the same rationale for all: Each search should concern at least one term related to PTSD and the keyword virtual reality.

The studies included should fulfill the following criteria: (1) have their own empirical data; (2) published between 1999 and 2011; (3) written in English, Spanish, or Portuguese languages; (4) sample of adults with diagnostic criteria for PTSD, according to DSM-V or DSM-IV-TR, determined by the researchers; and (5) the intervention should consist of exposure to virtual reality.

\section{Results}

The searches were conducted by the author MR, who is responsible for the searches and the publications retrieval. Several book reviews, book chapters, and congress proceedings were found, as well as theoretical and empirical articles-in total, 241 publications. Afterwards, the retrieved full-text publications were assessed by two independent judges and, after theirs consensus meeting, a total of 28 publications were selected for this review (see Figure 1). 


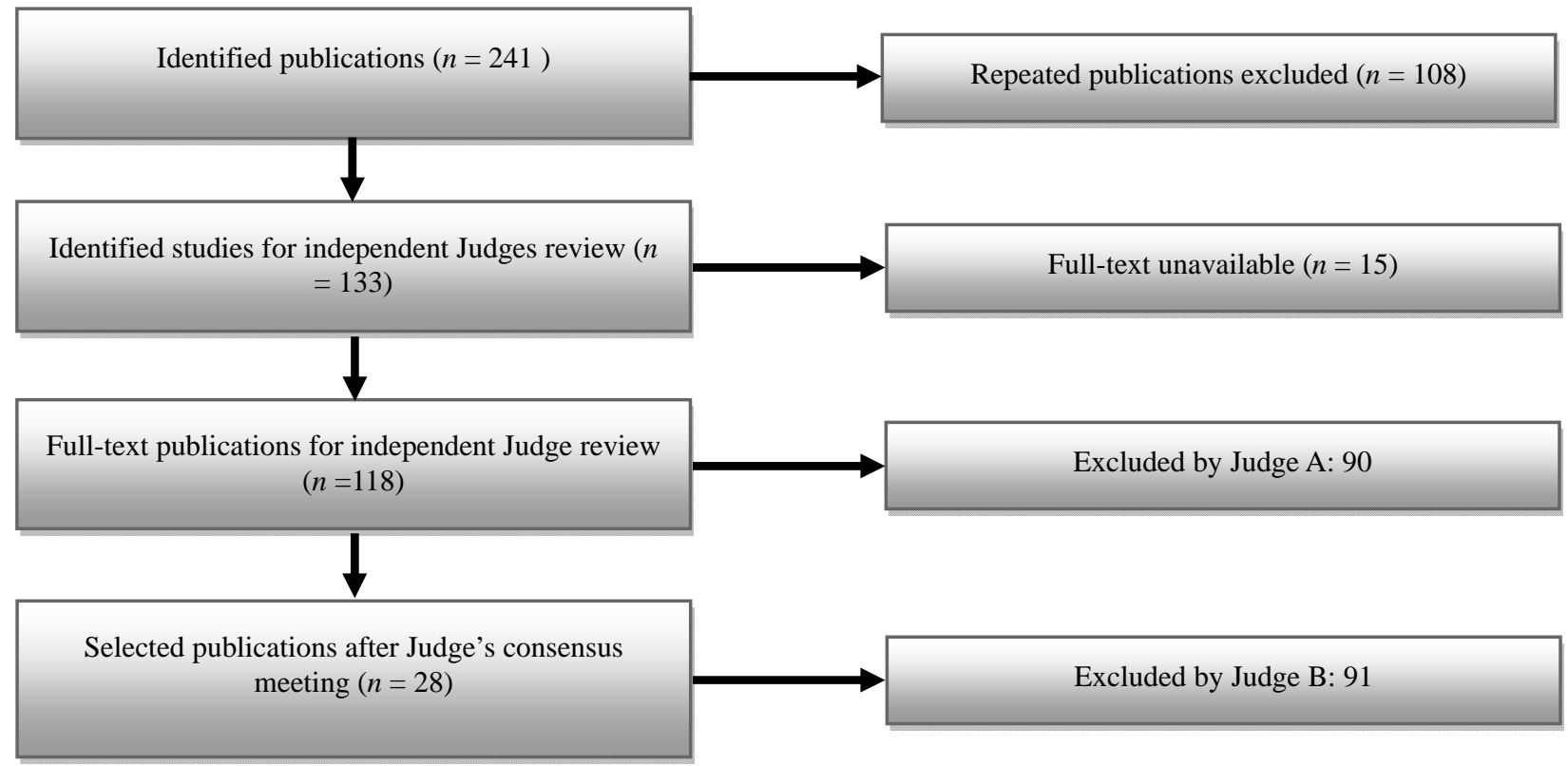

Figure 1. Studies selection.

In the 28 studies included in this review, individuals with PTSD diagnostic underwent exposure therapy with the use of VR. The majority were case studies $(n=11)$; uncontrolled case series $(n=8)$ and randomized controlled trials $(n=9)$ were also included. When observed according to the main stressful event, four different situations could be identified: the attacks of September 11 on the World Trade Center, the Iraq War, the Vietnam War, motor vehicle accident, robbery at the workplace, and street and domestic violence. The total sample was composed of 204 patients.

The treatment showed a wide range in the number of sessions with VR exposure, ranging between 3 and 22 sessions $(M=9.09, S D=1.57)$, and in the techniques used alongside VR exposure, such as: relaxation training, psychoeducation, meditation, imagistic exposure, attentional refocusing, and cognitive restructuring. Most studies provided weekly or twice a week sessions of 90 minutes each. The PTSD diagnosis and measurement of its symptomatology were assessed by the CAPS (clinician-administered PTSD scale) (Blake et al., 1995), SCID (structured clinical interview for the DSM-IV) (First, Spitzer, Gibbon, \& Williams, 2002), MINI neuropsychiatric interview (Sheehan et al., 1998), PDS (post-traumatic diagnostic scale) (Foa, Cashman, Jaycox, \& Perry, 1997), THQ (trauma history questionnaire) (Green, 1996), PCL (PTSD checklist) (Weathers, Litz, Herman, Huska, \& Keane, 1993), PSS-SR (PTSD symptoms scale self-report) (Foa, Riggs, Dancu, \& Rothbaum, 1993), PCL-M (PTSD checklist military version) (Weathers, Huska, \& Keane, 1991), and IES-R (impact of event scale) (Weiss \& Marmar, 2004).

Another source of variability came from how each study reported results. The findings will be reported here in groups according to study design: (1) case study; (2) uncontrolled case series; and (3) randomized controlled trials. Among the case studies, the results were promising; all studies were able to reduce the PTSD symptomatology: (1) subjects no longer fulfilled criteria for PTSD diagnostic (Freedman et al., 2010; Reger \& Gahm, 2008; Wood, Webb-Murphy et al., 2009); (2) a statistically significant reduction $(p<0.05)$ in PTSD symptomatology according to CAPS (Gerardi, Rothbaum, Ressler, Heekin, \& Rizzo, 2008); (3) clinically significant reduction, yet non-statistical significance was presented, in PTSD symptoms (Difede \& 
Hoffman, 2002; Miyahira, Folen, Hoffman, Garcia-Palacios, \& Schaper, 2010; Rothbaum et al., 1999; Rothbaum, Ruef, Litz, Han, \& Hodges, 2003; Saraiva et al., 2007; Tworus, Szymanska, \& Ilnicki, 2010; Wood et al., 2006).

As regards the uncontrolled case series, overall they showed promising results (see Table 1). The sample ranged from 2 to 24 participants $(M=12.3$; $S D=7.7)$, the number of treatment sessions ranged from 7 to 20 , and the number of sessions with virtual reality ranged from 3 to $18(M=10.7 ; S D=5.6)$. It is worth noting that only two studies did not report the use of combined techniques (Ready, Pollack, Rothbaum, \& Alarcon, 2006; Reger et al., 2011), while others employed several others (relaxation methods being the most mentioned). In two studies of combat related PTSD, the participants no longer met criteria at the end of treatment (Roy et al., 2008; Wood et al., 2009), while the rest presented significant symptoms reductions according to the respective instruments.

In relation to the randomized clinical trials (see Table 2), it was found a wide variation concerning the VRE intervention as well as combined and control intervention. The samples ranged from 5 to 21 participants $(M=13.3 ; S D=5.7)$. The number of sessions of the VRE treatment ranged from 5 to 14 sessions, and the sessions with VRE accounted for 5 to 8 sessions $(M=7.5$; $S D=1.6)$. Combined interventions were less used when compared with the uncontrolled case series (see Table 1), yet imagistic exposure, anxiety control training, and unspecific CBT techniques were reported. As for the control group, waitlist was the most employed, followed by treatment as usual. The majority of the studies presented significant results, except Roy et al. (2008), who found modest results, and Gamito et al. (2009), who found no significant differences. For further scrutiny of Gamito et al. (2010), Botella et al. (2010), McLay, McBrien, M. D. Wiederhold, and B. K. Wiederhold (2010), and Ready, Gerardi, Backscheider, Mascaro, and Rothbaum (2010), see Gonçalves et al. (2012).

Table 1

Uncontrolled Case Series

\begin{tabular}{|c|c|c|c|c|c|c|}
\hline Study & $\begin{array}{l}\text { PTSD } \\
\text { assessment }\end{array}$ & Sample & $\begin{array}{l}\mathrm{RV} \\
\text { sessions }\end{array}$ & $\begin{array}{l}\text { Total } \\
\text { sessions }\end{array}$ & Combined interventions & Main findings \\
\hline $\begin{array}{l}\text { Wood et al. } \\
(2009)^{44}\end{array}$ & CAPS, PCL-M & 12 & 18 & 20 & $\begin{array}{l}\text { Meditation, attentional } \\
\text { refocusing }\end{array}$ & No PTSD \\
\hline $\begin{array}{l}\text { Wiederhold et al. } \\
(2010)^{45}\end{array}$ & PCL-M & 2 & 18 & 20 & $\begin{array}{l}\text { Meditation, } \\
\text { progressive relaxation training, } \\
\text { attentional refocusing, } \\
\text { paced abdominal breathing }\end{array}$ & No PTSD \\
\hline $\begin{array}{l}\text { Walshe et al. } \\
(2003)^{56}\end{array}$ & FDI, CAPS & 7 & 12 & 12 & $\begin{array}{l}\text { Diaphragmatic respiration } \\
\text { training, } \\
\text { cognitive restructuring }\end{array}$ & $\begin{array}{l}\text { Significant symptom reduction } \\
\text { SUDS }(p=0.008) ; \text { FDI }(p= \\
0.008) \text {; CAPS }(p=0.008) ; \operatorname{HR}(p= \\
0.008)\end{array}$ \\
\hline $\begin{array}{l}\text { Reger et al. } \\
(2011)^{42}\end{array}$ & PCL-M, & 24 & 3 & 7.4 & - & $\begin{array}{l}\text { Significant symptom reduction } \\
(M=47.08 ; S D=12.70 ; p<0.001)\end{array}$ \\
\hline $\begin{array}{l}\text { Rizzo et al. } \\
(2010)^{57}\end{array}$ & PCL-M, PHQ-9 & 20 & 7 & 10 & Imagistic exposure & $\begin{array}{l}\text { Significant symptom reduction } \\
(t=5.99, d f=19, p<0.001)\end{array}$ \\
\hline $\begin{array}{l}\text { Ready et al. } \\
(2006)^{43}\end{array}$ & $\begin{array}{l}\text { CAPS, IES } \\
\text { SUDS }\end{array}$ & 14 & 9 & 10 & - & $\begin{array}{l}\text { Significant symptom reduction } \\
(p<0.0001)\end{array}$ \\
\hline $\begin{array}{l}\text { Beck et al. } \\
(2007)^{58}\end{array}$ & $\begin{array}{l}\text { CAPS, PSS-SR, } \\
\text { CSQ, SSQ, }\end{array}$ & 8 & 8 & 10 & Relaxation training & $\begin{array}{l}\text { Significant symptom reduction } \\
\text { CAPS total }(p<0.05)\end{array}$ \\
\hline $\begin{array}{l}\text { Rothbaam et al. } \\
(2001)^{59}\end{array}$ & CAPS, IES & 6 & $4-15$ & $8-16$ & $\begin{array}{l}\text { Imagistic exposure, brief } \\
\text { breathing relaxation method }\end{array}$ & $\begin{array}{l}\text { Significant symptom reduction } \\
\text { post-treatment }(p=0.0727) \text { and at } \\
\text { six month follow-up }(p=0.0021)\end{array}$ \\
\hline
\end{tabular}


Table 2

Randomized Clinical Trials

\begin{tabular}{|c|c|c|c|c|c|c|c|}
\hline Study & $\begin{array}{l}\text { PTSD } \\
\text { assessment }\end{array}$ & Sample & $\begin{array}{l}\text { VR } \\
\text { sessions }\end{array}$ & $\begin{array}{l}\text { Total } \\
\text { sessions }\end{array}$ & $\begin{array}{l}\text { Combined } \\
\text { interventions }\end{array}$ & Control intervention & Main findings \\
\hline $\begin{array}{l}\text { Roy et al. } \\
(2008)^{45}\end{array}$ & $\begin{array}{l}\text { PCL-M, } \\
\text { CAPS, SCID }\end{array}$ & 13 & 8 & 12 & CBT & $\mathrm{PE}$ & Modest symptom reduction \\
\hline $\begin{array}{l}\text { Ready et al. } \\
(2010)^{50}\end{array}$ & CAPS, SCID & 11 & - & 10 & $\begin{array}{l}\text { Imagistic } \\
\text { exposure }\end{array}$ & $\begin{array}{l}\text { Present centered } \\
\text { therapy }\end{array}$ & $\begin{array}{l}\text { Post-treatment and follow-up } \\
\text { significant effect sizes (Cohen's } d \\
=0.28 \text { and } 0.56 \text { ) }\end{array}$ \\
\hline $\begin{array}{l}\text { McLay et al. } \\
(2010)^{49}\end{array}$ & $\begin{array}{l}\text { PCL-M, } \\
\text { PHQ-9 }\end{array}$ & 10 & - & 6.5 & $\begin{array}{l}\text { Anxiety control } \\
\text { training }\end{array}$ & $\begin{array}{l}\text { Exposure therapy } \\
\text { (Foa's protocol) }\end{array}$ & $\begin{array}{l}\text { Significant difference between } \\
\text { pre- and post-treatment }(p< \\
0.001) \text {, no group differences }\end{array}$ \\
\hline $\begin{array}{l}\text { McLay et al. } \\
(2011)^{51}\end{array}$ & CAPS & 20 & 8.8 & 10 & - & Treatment as usual & $\begin{array}{l}\text { Significant difference between } \\
\text { groups, over the course of } \\
\text { treatment ( } 35.4 \text { vs. } 9.4, p<0.05)\end{array}$ \\
\hline $\begin{array}{l}\text { Gamito et al. } \\
(2009)^{46}\end{array}$ & $\begin{array}{l}\text { CAPS, } \\
\text { IES-R, } \\
\text { SCL-90R }\end{array}$ & 5 & 5 & 5 & - & $\begin{array}{l}\text { Waiting list or } \\
\text { traditional } \\
\text { psychotherapy }\end{array}$ & No significant differences \\
\hline $\begin{array}{l}\text { Gamito et al. } \\
(2010)^{47}\end{array}$ & $\begin{array}{l}\text { CAPS, } \\
\text { IES-R, } \\
\text { SCL-90R }\end{array}$ & 10 & 11 & 12 & - & $\begin{array}{l}\text { Waiting list or } \\
\text { imagistical exposure }\end{array}$ & $\begin{array}{l}\text { Significant effect CAPS screening } \\
(p>0.05) \text {, CAPS reduction VRET } \\
(8 \%) \text {; EI }(1 \%) \text { and WL }(6 \%)\end{array}$ \\
\hline $\begin{array}{l}\text { Difede et al. } \\
(2006)^{61}\end{array}$ & CAPS, SCID & 20 & - & 14 & - & Waitinglist & $\begin{array}{l}\text { Significant effect size } \\
1.53 \text { and symptoms reduction } \\
\text { CAPS }(t=3.32, p=0.01)\end{array}$ \\
\hline $\begin{array}{l}\text { Botella et al. } \\
(2010)^{48}\end{array}$ & $\begin{array}{l}\text { CAPS, DTS, } \\
\text { PTCI }\end{array}$ & 10 & 5 & 9 & CBT & $\mathrm{CBT}$ & $\begin{array}{l}\text { Significant reduction on CAPS }(Z \\
=2.032 ; p<0.04) \text { and PTCI }(Z= \\
2.032 ; p<0.04)\end{array}$ \\
\hline $\begin{array}{l}\text { Difede et al. } \\
(2007)^{62}\end{array}$ & $\begin{array}{l}\text { CAPS, PCL, } \\
\text { GSI, THQ }\end{array}$ & 21 & 7.3 & 14 & - & Waitinglist & $\begin{array}{l}\text { Significant effect between-groups } \\
1.54\end{array}$ \\
\hline
\end{tabular}

\section{Discussion}

The present review compiled several VRET for PTDS studies, most of which reported the intervention as effective and more effective when compared with waitlist and treatment as usual. This suggests that given the correct conditions, the use of virtual reality can be an asset in the treatment of PTSD, which may be due to the possible increase in the emotional engagement and the therapist control over the exposition process.

The use of virtual reality in exposure techniques has been studied in a wide range of anxiety disorders, including specific phobia, social phobia, panic disorder, and PTSD with encouraging results. Even though Powers and Emmelkamp (2008) were able to gather a number of independent studies with VRET, only one of these was with PTSD patients. Although we were not able to perform a meta-analysis of the present data, the present findings point in the same direction.

As previously stated, Gonçalves et al. (2012) performed a similar review, although they differ in the following aspects: (1) There are a few month between the two searches, ours were made in September, 2011, while theirs in May, 2011; (2) The databases were the same, although we also searched EBSCO end SciELO/Pepsic; and (3) Our review had a broader scope (all empirical data), while Gonçalves et al. narrowed theirs to 10 studies, excluding case studies and subclinical PTSD. Given the interventions novelty, we consider the broaden search and more liberal criteria as an advantage.

The present review presents an array of studies with a wide variation concerning design, sample, and the intervention itself as well as the control intervention, when used. Arguably, the sample variation can be positive, providing data that the intervention works in different populations, including samples that already failed to improve having gone through the treatment as usual (McLay et al., 2011). The findings of this study suggest 
that the use of virtual reality as a tool for exposure therapy for PTSD can be an asset, although there is an evident need for studies with better methodology, bigger samples, and randomized control trial designs that concern control groups with other interventions like imaginal exposure and "in vivo" exposure.

The use of virtual reality in the treatment for PTSD is based on the premises of PE (Rothbaum et al., 2008), which aims to reduce the anxiety paired with trauma related situations as well as restructure the trauma memory. The mechanisms underlying the PTSD development and remission are still a subject of spirited debate in the scientific community and several models have been proposed. With regard to how the memory behaves, Brewin, Dalgleish, and Joseph (1996) proposed two separate memory systems, VAM (verbally accessible memory), which is overall cohesive with autobiographical memory and can be intentionally retrieved, and the SAM (situationally accessible memory), which is not deliberately retrieved, usually comes in flashbacks triggered by trauma related situations, and consists generally of sensorial and image memories. It is hypothesized that the exposure treatments seek to create new SAM memories with lower emotional valence that overcome the traumatic ones, and aim to put these memories into a rational and autobiographical context.

The present findings point toward a novel way to treat PTSD through exposure. With the exponential advances in computer simulations, the future possibilities are impossible to foresee, although it may directly interfere with the presence factor. Presence can be defined as the perception of being in the virtual environment. It has been shown to play an important role in treatments involving virtual reality (Alsina-Jurnet, Gutiérrez-Maldonado, \& Rangel-Gómez, 2011; Price \& Anderson, 2007; Price, Mehta, Tone, \& Anderson, 2011). This can be an important aspect to be taken in account concerning patients with difficulties to engage emotionally in exposure treatments as well as when the traumatic situation is pragmatically impossible to recreate for an "in vivo" exposure.

Despite the methodological variability found in the selected publications, the intervention showed itself as a promising option for PTSD treatment. Overall, the studies in this review presented positive results toward the aimed intervention. More research in the field is needed in order refine the understanding the mechanisms underlying the intervention and to create a standardized protocol.

\section{References}

Alsina-Jurnet, I., Gutiérrez-Maldonado, J., \& Rangel-Gómez, M. V. (2011). The role of presence in the level of anxiety experienced in clinical virtual environments. Computers in Human Behavior, 27(1), 504-512.

American Psychiatric Association. (2000). Diagnostic and statistical manual of mental disorders: DSM-IV-TRß. American Psychiatric Pub.

Ballenger, J. C., Davidson, J. R. T., Lecrubier, Y., Nutt, D. J., Marshall, R. D., Nemeroff, C. B.,... Yehuda, R. (2004). Consensus statement update on posttraumatic stress disorder from the international consensus group on depression and anxiety. Journal of Clinical Psychiatry, 65, 55-62.

Beck, J. G., Palyo, S. A., Winer, E. H., Schwagler, B. E., \& Ang, E. J. (2007). Virtual reality exposure therapy for PTSD symptoms after a road accident: An uncontrolled case series. Behavior Therapy, 38(1), 39-48.

Bisson, J. I., Ehlers, A., Matthews, R., Pilling, S., Richards, D., \& Turner, S. (2007). Psychological treatments for chronic post-traumatic stress disorder Systematic review and meta-analysis. The British Journal of Psychiatry, 190(2), 97-104.

Blake, D. D., Weathers, F. W., Nagy, L. M., Kaloupek, D. G., Gusman, F. D., Charney, D. S., \& Keane, T. M. (1995). The development of a clinician-administered PTSD scale. Journal of Traumatic Stress, 8(1), 75-90.

Botella, C., García-Palacios, A., Guillen, V., Baños, R. M., Quero, S., \& Alcaniz, M. (2010). An adaptive display for the treatment of diverse trauma PTSD victims. Cyberpsychology, Behavior, and Social Networking, 13(1), 67-71.

Bradley, R., Greene, J., Russ, E., Dutra, L., \& Westen, D. (2005). A multidimensional meta-analysis of psychotherapy for PTSD. American Journal of Psychiatry, 162(2), 214-227. 
Breslau, N. (2002). Epidemiologic studies of trauma, posttraumatic stress disorder, and other psychiatric disorders. Canadian Journal of Psychiatry, 47, 923-929.

Brewin, C. R., Dalgleish, T., \& Joseph, S. (1996). A dual representation theory of posttraumatic stress disorder. Psychological Review, 103(4), 670.

Cahill, S. P., \& Foa, E. B. (2007). Psychological theories of PTSD. In M. J. Friedman, T. M. Keane, \& P. A. Resick (Eds.), Handbook of PTSD: Science and practice (pp. 55-77). New York, USA: Guilford Press.

Difede, J., Cukor, J., Jayasinghe, N., Patt, I., Jedel, S., Spielman, L., . . Hoffman, H. G. (2007). Virtual reality exposure therapy for the treatment of posttraumatic stress disorder following September 11, 2001. Journal of Clinical Psychiatry, 68(11), 1639-1647.

Difede, J., Cukor, J., Patt, I., Giosan, C., \& Hoffman, H. (2006). The application of virtual reality to the treatment of PTSD following the WTC attack. Annals of the New York Academy of Sciences, 1071(1), 500-501.

Difede, J., \& Hoffman, H. G. (2002). Virtual reality exposure therapy for World Trade Center post-traumatic stress disorder: A case report. Cyberpsychology \& Behavior, 5(6), 529-535.

First, M. B., Spitzer, R. L., Gibbon, M., \& Williams, J. B. W. (2002). Structured clinical interview for DSM-IV-TR axis I disorders (research version, non-patient edition: SCID-I/P, biometrics research). New York: New York State Psychiatric Institute.

Foa, E. B., Cashman, L., Jaycox, L., \& Perry, K. (1997). The validation of a self-report measure of posttraumatic stress disorder: the Posttraumatic Diagnostic Scale. Psychological Assessment, 9(4), 445.

Foa, E. B., \& Kozak, M. J. (1986). Emotional processing of fear: Exposure to corrective information. Psychological Bulletin, 99(1), 20.

Foa, E. B., Riggs, D. S., Dancu, C. V., \& Rothbaum, B. O. (1993). Reliability and validity of a brief instrument for assessing post-traumatic stress disorder. Journal of Traumatic Stress, 6(4), 459-473.

Freedman, S. A., Hoffman, H. G., Garcia-Palacios, A., Weiss, P. L., Avitzour, S., \& Josman, N. (2010). Prolonged exposure and virtual reality-enhanced imaginal exposure for PTSD following a terrorist bulldozer attack: A case study. Cyberpsychology, Behavior, and Social Networking, 13(1), 95-101.

Gamito, P., Oliveira, J., Morais, D. et al. (2009). Virtual reality therapy controlled study for war veterans with PTSD: Preliminary results. Annual Review of Cybertherapy and Telemedicine, 7, 269-271.

Gamito, P., Oliveira, J., Rosa, P., Morais, D., Duarte, N., Oliveira, S., \& Saraiva, T. (2010). PTSD elderly war veterans: A clinical controlled pilot study. Cyberpsychology, Behavior, and Social Networking, 13(1), 43-48.

Gerardi, M., Rothbaum, B. O., Ressler, K., Heekin, M., \& Rizzo, A. (2008). Virtual reality exposure therapy using a virtual Iraq: case report. Journal of Traumatic Stress, 21(2), 209-213.

Gonçalves, R., Pedrozo, A. L., Coutinho, E. S. F., Figueira, I., \& Ventura, P. (2012). Efficacy of virtual reality exposure therapy in the treatment of PTSD: A systematic review. PloS one, 7(12), e48469.

Green, B. L. (1996). Trauma history questionnaire. Measurement of Stress, Trauma, and Adaptation, 1, 366-369.

Kessler, R. C. (1995). The national comorbidity survey: Preliminary results and future directions. International Journal of Methods in Psychiatric Research, 5(2), 139-151.

Kessler, R. C., Chiu, W. T., Demler, O., \& Walters, E. E. (2005). Prevalence, severity, and comorbidity of 12-month DSM-IV disorders in the national comorbidity survey replication. Archives of General Psychiatry, 62(6), 617.

McLay, R. N., McBrien, C., Wiederhold, M. D., \& Wiederhold, B. K. (2010). Exposure therapy with and without virtual reality to treat PTSD while in the combat theater: A parallel case series. Cyberpsychology, Behavior, and Social Networking, 13(1), 37-42.

McLay, R. N., Wood, D. P., Webb-Murphy, J. A., Spira, J. L., Wiederhold, M. D., Pyne, J. M., \& Wiederhold, B. K. (2011). A randomized, controlled trial of virtual reality-graded exposure therapy for post-traumatic stress disorder in active duty service members with combat-related post-traumatic stress disorder. Cyberpsychology, Behavior, and Social Networking, 14(4), 223-229.

Mendes, D. D., Mello, M. F., Ventura, P., de Medeiros Passarela, C., \& de Jesus Mari, J. (2008). A systematic review on the effectiveness of cognitive behavioral therapy for posttraumatic stress disorder. The International Journal of Psychiatry in Medicine, 38(3), 241-259.

Mills, K., Teesson, M., Ross, J., \& Peters, L. (2006). Trauma, PTSD, and substance use disorders: Findings from the Australian national survey of mental health and well-being. American Journal of Psychiatry, 163(4), 652-658. 
Miyahira, S. D., Folen, R. A., Hoffman, H. G., Garcia-Palacios, A., \& Schaper, K. M. (2010). Effectiveness of brief VR treatment for PTSD in war-fighters: A case study. Stud Health Technol Inform, 154, 214-219.

Mowrer, O. (1960). Learning theory and behavior. Hoboken, N.J.: John Wiley \& Sons Inc..

Olatunji, B. O., Cisler, J. M., \& Deacon, B. J. (2010). Efficacy of cognitive behavioral therapy for anxiety disorders: A review of meta-analytic findings. Psychiatric Clinics of North America, 33(3), 557-577.

Powers, M. B., \& Emmelkamp, P. M. G. (2008). Virtual reality exposure therapy for anxiety disorders: A meta-analysis. Journal of Anxiety Disorders, 22(3), 561-569.

Price, M., \& Anderson, P. (2007). The role of presence in virtual reality exposure therapy. Journal of Anxiety Disorders, 21(5), 742-751.

Price, M., Mehta, N., Tone, E. B., \& Anderson, P. L. (2011). Does engagement with exposure yield better outcomes? Components of presence as a predictor of treatment response for virtual reality exposure therapy for social phobia. Journal of Anxiety Disorders, 25(6), 763-770.

Ready, D. J., Gerardi, R. J., Backscheider, A. G., Mascaro, N., \& Rothbaum, B. O. (2010). Comparing virtual reality exposure therapy to present-centered therapy with 11 US Vietnam veterans with PTSD. Cyberpsychology, Behavior, and Social Networking, 13(1), 49-54.

Ready, D. J., Pollack, S., Rothbaum, B. O., \& Alarcon, R. D. (2006). Virtual reality exposure for veterans with posttraumatic stress disorder. Journal of Aggression, Maltreatment \& Trauma, 12(1-2), 199-220.

Reger, G. M., \& Gahm, G. A. (2008). Virtual reality exposure therapy for active duty soldiers. Journal of Clinical Psychology, 64(8), 940-946.

Reger, G. M., Holloway, K. M., Candy, C., Rothbaum, B. O., Difede, J., Rizzo, A. A., \& Gahm, G. A. (2011). Effectiveness of virtual reality exposure therapy for active duty soldiers in a military mental health clinic. Journal of Traumatic Stress, 24(1), 93-96.

Riggs, D. S., Cahill, S. P., Foa, E. B., Follette, V. M., \& Ruzek, J. I. (2006). Prolonged exposure treatment of posttraumatic stress disorder. In M. J. Friedman, T. M. Keane, \& P. A. Resick (Eds.), Cognitive-behavioral therapies for trauma (pp. 65-95). New York, USA: Guilford Press.

Rizzo, A., Difede, J., Rothbaum, B. O., Reger, G., Spitalnick, J., Cukor, J., \& Mclay, R. (2010). Development and early evaluation of the Virtual Iraq/Afghanistan exposure therapy system for combat-related PTSD. Annals of the New York Academy of Sciences, 1208(1), 114-125.

Rothbaum, B. O., Hodges, L. F., Ready, D., Graap, K., \& Alarcon, R. D. (2001). Virtual reality exposure therapy for Vietnam veterans with posttraumatic stress disorder. Journal of Clinical Psychiatry, 62(8), 617-622.

Rothbaum, B. O., Meadows, E. A., Resick, P. A., \& Foy, D. W. (2008). Cognitive-behavioral therapy. In E. B. Foa, T. M. Keane, M. J. Friedman, \& J. A. Cohen (Eds.), Effective treatments for PTSD: Practice guidelines from the International Society for Traumatic Stress Studies (pp. 60-83). Guilford Press.

Rothbaum, B. O., Hodges, L., Alarcon, R., Ready, D., Shahar, F., Graap, K.,...Wills, B. (1999). Virtual reality exposure therapy for PTSD Vietnam veterans: A case study. Journal of Traumatic Stress, 12(2), 263-271.

Rothbaum, B. O., Ruef, A. M., Litz, B. T., Han, H., \& Hodges, L. (2003). Virtual reality exposure therapy of combat-related PTSD: A case study using psychophysiological indicators of outcome. Journal of Cognitive Psychotherapy, 17(2), 163-178.

Roy, M. J., Francis, J., Friedlander, J. et al. (2008). Initial results from the ViRTiCo trial: Virtual reality therapy and imaging in combat veterans. Annual Review of CyberTherapy and Telemedicine, 6, 47-52.

Saraiva, T., Gamito, P., Oliveira, J., Morais, D., Pombal, M., Gamito, L., \& Anastácio, M. (2007). The use of VR exposure in the treatment of motor vehicle PTSD: A case report. Annual Review of CyberTherapy and Telemedicine, 5, 199-205.

Schnurr, P. P., Green, B. L., \& Kaltman, S. (2007). Trauma exposure and physical health. In M. J. Friedman, T. M. Keane, \& P. A. Resick (Eds.), Handbook of PTSD: Science and practice (pp. 406-424). New York, USA: Guilford Press.

Sheehan, D. V., Lecrubier, Y., Sheehan, K. H., Amorim, P., Janavs, J., Weiller, E.,... Dunbar, G. C. (1998). The mini-international neuropsychiatric interview (MINI): The development and validation of a structured diagnostic psychiatric interview for DSM-IV and ICD-10. Journal of Clinical Psychiatry, 59, 22-33.

Taylor, S. (2006). Clinician's guide to PTSD: A cognitive-behavioral approach. Guilford Press.

Thomas, J. L., Wilk, J. E., Riviere, L. A., McGurk, D., Castro, C. A., \& Hoge, C. W. (2010). Prevalence of mental health problems and functional impairment among active component and national guard soldiers 3 and 12 months following combat in Iraq. Archives of General Psychiatry, 67(6), 614. 
Tworus, R., Szymanska, S., \& Ilnicki, S. (2010). A soldier suffering from PTSD, treated by controlled stress exposition using virtual reality and behavioral training. Cyberpsychology, Behavior, and Social Networking, 13(1), 103-107.

Walshe, D. G., Lewis, E. J., Kim, S. I., O’Sullivan, K., \& Wiederhold, B. K. (2003). Exploring the use of computer games and virtual reality in exposure therapy for fear of driving following a motor vehicle accident. CyberPsychology \& Behavior, 6(3), 329-334.

Weathers, F., Huska, J., \& Keane, T. (1991). The PTSD checklist military version (PCL-M). Boston, M.A.: National Center for PTSD.

Weathers, F. W., Litz, B. T., Herman, D. S., Huska, J. A., \& Keane, T. M. (1993). The PTSD checklist (PCL): Reliability, validity, and diagnostic utility. Paper presented at the Annual Meeting of the International Society for Traumatic Stress Studies, San Antonio, T.X..

Weiss, D. S., \& Marmar, C. R. (2004). The impact of event scale-revised. Assessing psychological trauma and PTSD, 2, 168-189.

Wiederhold, B. K., \& Wiederhold, M. D. (2004). Virtual reality therapy for anxiety disorders: Advances in evaluation and treatment. American Psychological Association.

Wood, D. P., Murphy, J., Center, K., McLay, R., Reeves, D., Pyne, J.,... Wiederhold, B. K. (2006). Combat-related post-traumatic stress disorder: A case report using virtual reality exposure therapy with physiological monitoring. Cyberpsychology \& Behavior, 10(2), 309-315.

Wood, D. P., Murphy, J., McLay, R., Koffman, R., Spira, J., Obrecht, R. E.,... Wiederhold, B. K. (2009). Cost effectiveness of virtual reality graded exposure therapy with physiological monitoring for the treatment of combat related post traumatic stress disorder. Stud Health Technol Inform, 144, 223-229.

Wood, D. P., Webb-Murphy, J., Center, K., McLay, R., Koffman, R., Johnston, S.,... Wiederhold, B. K. (2009). Combat-related post-traumatic stress disorder: A case report using virtual reality graded exposure therapy with physiological monitoring with a female Seabee. Military Medicine, 174(11), 1215-1222.

Wood, D. P., Wiederhold, B. K., \& Spira, J. (2010). Lessons learned from 350 virtual-reality sessions with warriors diagnosed with combat-related posttraumatic stress disorder. Cyberpsychology, Behavior, and Social Networking, 13(1), 3-11. 